\title{
Spatio-Temporal Measurement of Indoor Particulate Matter Concentrations Using a Wireless Network of Low-Cost Sensors in Households Using Solid Fuels
}

\author{
Sameer Patel ${ }^{\mathrm{a}}$, Jiayu Li ${ }^{\mathrm{a}}$, Apoorva Pandey ${ }^{\mathrm{a}}$, Shamsh Pervez ${ }^{\mathrm{b}}$, Rajan K. Chakrabarty ${ }^{\mathrm{a}}$, Pratim \\ $\operatorname{Biswas}^{a_{*}}$ \\ a. Center for Aerosol Science and Engineering (CASE) \\ Department of Energy, Environmental and Chemical Engineering, \\ Washington University in St. Louis, \\ One Brookings Drive, St. Louis, MO 63130, USA \\ b. School of Studies in Chemistry, \\ Pandit Ravishankar Shukla University, \\ Amanaka G.E.Road, Raipur, Chhattisgarh 492010, India
}

Submitted to

\section{Environmental Research}

Original Version Submission: July 7, 2016

Revised Version Submission: August 18, 2016

*To whom correspondence should be addressed.

Tel: +1-314-935-5548 Fax: +1-314-935-5464

E-mail address: pbiswas@wustl.edu 


\begin{abstract}
Many households use solid fuels for cooking and heating purposes. There is currently a knowledge gap in our understanding of the variations in indoor air quality throughout the household as most of the studies focus on the areas in the close proximity of the cookstove. A low-cost wireless particulate matter (PM) sensor network was developed and deployed in households in Raipur, India to establish the spatio-temporal variation of PM concentrations. The data from multiple sensors were acquired in real-time with a wireless system. Data collected from the sensors agreed well $\left(\mathrm{R}^{2}=0.713\right)$ with the reference data collected from a commercially available instrument. Low spatial variability was observed within the kitchen due to its small size and poor ventilation - a common feature of most rural Indian kitchens. Due to insufficient ventilation from open doors and windows, high PM concentrations similar to those found in the kitchen were also found in the adjoining rooms. The same household showed significantly different post-extinguished cookstove PM concentration decay rates $\left(0.26 \mathrm{mg} / \mathrm{m}^{3}-\mathrm{min}\right.$ and 0.87 $\left.\mathrm{mg} / \mathrm{m}^{3}-\mathrm{min}\right)$ on different days, owing to varying natural air exchange rates $\left(7.68 \mathrm{~m}^{3} / \mathrm{min}\right.$ and $\left.37.40 \mathrm{~m}^{3} / \mathrm{min}\right)$.
\end{abstract}

\title{
Keywords
}

Spatio-temporal $\mathrm{PM}_{2.5}$; indoor air quality; cookstoves; household air pollution; low-cost instrumentation 


\section{Introduction}

Spatio-temporal monitoring of outdoor and indoor air quality provides critical information about emissions sources, air flow and ventilation, and subsequent personal exposure. For example, in highly polluted cities like Delhi, India, and Beijing, China [1], measurements at a few locations cannot represent pollution levels in the whole city. Similarly, at a much smaller scale, household air pollution measurements near pollution sources such as a furnace or cookstove are insufficient to accurately estimate personal exposure in different parts of the households over different durations. Spatio-temporal pollutant level data provides a way to better model the effect of air circulation on pollutant dispersion and decay rate.

Better characterization of indoor air pollution is critical because residents spend much more time indoors than they spend outdoors [2-4]. The World Health Organization (WHO) reported that poor indoor air quality due to residential solid fuel combustion affects over three billion people. Particulate matter (PM) emissions cause health issues such as acute respiratory infections (ARI), chronic obstructive pulmonary disease (COPD), and cataracts [5-9]. WHO has estimated four million premature deaths from illness are attributable to household air pollution from residential solid fuel combustion for cooking and heating [10]. Furthermore, among children under the age of five, pneumonia attributed to inhaled PM accounts for more than half of the total deaths.

The majority of published studies on solid fuel cookstoves and indoor air quality take $\mathrm{PM}_{2.5}$ (particulate matter less than $2.5 \mu \mathrm{m}$ in aerodynamic diameter) measurements using gravimetric methods at limited locations to indicate the levels of personal exposure [11-14]. Real time measurements have only been reported from few field studies on cookstove emissions [15, 
16] but data on spatial variation of the pollutants in indoor environments is limited because of use of few instruments due to their high cost. Most previous studies have taken measurements near the breathing zone $[12,17-19]$ or above the cookstove [20] which might not be representative of indoor air quality throughout the household. Sampling near the source does not capture parameters other than the source characteristics, a shortcoming that affects the assessment of overall indoor air quality.

The type of cookstove and fuel are not the only factors governing indoor air quality: other factors such as the household layout, kitchen volume, and ventilation characteristics also play important roles which are currently understudied [21-24]. Depending on the household characteristics, cookstove emissions can quickly transport to living spaces, thereby affecting other household members $[25,26]$. A large variation in personal exposure levels have been observed in different field studies, which is attributed to inability to capture the interplay between the household characteristics and indoor air quality [27]. Moreover, pollutants can stratify vertically exposing individuals with different heights, standing at the same location, to different levels of the same pollutant [22].

Spatio-temporal measurements are essential to correctly estimate personal exposure and to enhance the understanding of household air pollution, but such measurements are currently challenging to accomplish due to the lack of affordable real-time monitors [27]. To ensure the feasibility of using multiple devices for PM measurement, it is essential that low cost PM sensors be developed and deployed. Recent developments by many researchers in the design and fabrication of low-cost PM sensors [28-34] have made progress toward making such measurements feasible. 
The objectives of this study were to deploy a wireless PM sensor network for performance evaluation in households and to demonstrate its utility in providing insights into spatio-temporal distribution of indoor air pollution. Two households in Raipur, central India, using solid fuel cookstoves were selected for this research. To record spatio-temporal PM levels, multiple sensors, sending data wirelessly to a data acquisition system, were installed at different locations in the kitchen and adjoining parts of the household. A commercially available TSI Sidepak (TSI Inc., Minnesota, USA) was collocated with one of the sensors for performance comparison.

\section{Methods}

\subsection{Instrumentation}

A key feature of the study was the deployment of multiple low-cost PM sensors and using a wireless network system to collect the data. Sharp GP2Y1010AU0F sensors (Figure 1) were used in this study owing to their high linearity against the reference instrument (TSI SidePak AM 150) and long-time operational stability [28]. The operating principle of this sensor is the detection of scattered light from particles; the light source is an infrared emitting diode (IRED) and the detector is a phototransistor that converts the scattered light intensity to a voltage output. More details about the construction and operation principle of the Sharp GP2Y1010AU0F sensor are provided in a previous study [28]. Two additional components were attached to the sensors to enable wireless transmission of data and create a local area network (Figure 1). These components include a router (XBEE Series 2) to communicate with the data acquisition system. In this study, a coordinator connected to a computer was used for data collection and storage, but these sensors could readily be connected to the network cloud for real-time data acquisition and processing. Power was supplied to the sensors by $5 \mathrm{~V}$ lithium-ion batteries. The total cost of one 
sensor assembly including the Sharp GP2Y sensor, router, battery and accessories was around USD 50, making it much cheaper than any commercially available light-scattering based PM measurement instrument. The cost could be reduced to USD 25 provided the required parts are procured in bulk directly from the manufacturers.

The Sidepak and DustTrak (TSI Inc., Minnesota, USA), both with the same operating principle, have been used in multiple laboratory and field studies to measure $\mathrm{PM}_{2.5}$ mass concentrations from cookstoves [15, 16, 35-37]. A TSI Sidepak AM510 (approximate cost USD 3500) was used to record reference measurements to facilitate the sensor's performance evaluation. The Sidepak operation is also based on light scattering and uses a light source that is a $670 \mathrm{~nm}$ emitting diode. This instrument, which comes with impactors with different cut-off sizes, was operated with one to obtain $\mathrm{PM}_{2.5}$ concentrations. The Sidepak and the sensors were set to collect data with a frequency of $1 \mathrm{~Hz}$ and $0.25 \mathrm{~Hz}$ respectively.

\subsection{Household Characteristics and Test Plan}

The two households selected for this study used U-shaped mud cookstoves (chulhas) for cooking meals. The layout of each household is shown in Figure 2. The first household (Household A), shown in Figure 2A, had a kitchen (floor area $\sim 5.3 \mathrm{~m}^{2}$ ) on the second floor, isolated from the rest of the residential area on the first floor. The entrance door and a window next to it, both open during sampling, were the two main ventilation sources. The window area was permanently covered with a concrete slab consisting of multiple holes in a decorative pattern. The cookstove was located just below the window. The slightly slanted roof, a corrugated metal sheet, formed multiple small openings at the junction of the kitchen walls, and aided in the ventilation. No forced ventilation was present in Household A. The area outside the 
kitchen front was an open space for children to play, which was also used for air drying the biomass fuels. The PM sensors were installed at the five positions shown in Figure 2A. Sensors A1 and A2 were installed at the interface of the kitchen and ambient environment to capture the effects of natural dilution and air exchange between the two environments having different PM levels. Plume concentrations were captured by installing a sensor at position A3, directly above the cookstove. Another sensor was installed inside the kitchen at position A4 to investigate the spatial variability within the kitchen. Sensor A5 was installed outside of the kitchen to monitor PM levels corresponding to exposure levels of children present in that area.

Figure 2B presents the layout of the second household (Household B). With approximately $29 \mathrm{~m}^{2}$ of floor area, Household B consisted of a kitchen opening to a room which served as a living room; this room was further connected to a bedroom. The two rooms each had one door opening to the ambient environment (towards the backyard and street) providing natural ventilation. Similar to Household A, Household B had no forced ventilation. Only the windows and doors that were open during measurements, and therefore affected indoor air quality, are marked in the layout (Figure 2B). Household B had a thatched roof with pore spaces allowing emissions to escape through the ceiling. Multiple locations were chosen to install PM sensors. In the room adjoining the kitchen, PM levels were monitored at B1 and B3 (Figure 2B). Three sensors were placed at B2, B4, and B5 to investigate PM dispersion in the bedroom. A sensor at B6, around 4 feet outside the door, was installed to gauge dispersion and natural dilution of PM.

The SidePak was collocated with the sensor A3 in all of the runs in Household A. Due to physical constraints, it was not possible to place the Sidepak directly above the cookstove. Therefore, a sampling probe was hung over the cookstove at location A3, connected by a 
conductive silicon tubing (approximately 2.5 meter long) to the Sidepak. Sensor A3 was hung over the probe. The data from the collocated sensor and Sidepak was used to obtain calibration factors to convert the analog output from the sensors to Sidepak-equivalent $\mathrm{PM}_{2.5}$ levels. The calibration method and the measured spatio-temporal PM levels are discussed in detail in Section 3.1 .

Spatio-temporal PM measurements using the wireless sensor network were taken during multiple days at the two households. A summary of the experimental plan is given in Table 1. A total of six measurement runs were performed; four in Household A and two in Household B. A local meal was cooked during each run, and the cooking duration depended on the type of meal. In Household A, different types of biomass fuel were used, whereas dung cake was used for both runs in Household B.

\subsection{Data Analysis}

For ease of analysis, discussion of the spatio-temporal measurements has been divided into three sections: (1) pre-ignition (background), (2) the cooking phase, which starts with ignition and ends with extinguishing, and (3) the post-extinguished decay phase. Decay rates of pollutants after extinguishing the cookstove depend on the air exchange rate which is governed by the ventilation characteristics of the space. Average post-extinguished $\mathrm{PM}_{2.5}$ decay rates can be calculated by Eq. 1 where $P M_{2.5}^{0}$ and $P M_{2.5}^{t}$ are $P M_{2.5}$ concentrations at cookstove extinguishing and at any time t post-extinguished.

$$
\text { Decay rate }=\frac{P M_{2.5}^{0}-P M_{2.5}^{t}}{t}
$$

For the enclosed space i.e. the kitchen in Household A and the whole Household B, postextinguished $\mathrm{PM}_{2.5}$ decay can be modelled as Eq 2. In Eq. 2, V is the volume of the enclosed space, $\dot{v}$ is effective air exchange air rate, and $P M_{2.5}$ and $P M_{2.5}^{a m b}$ are $P M_{2.5}$ concentrations in the 
enclosed space and ambient respectively. Since ambient $\mathrm{PM}_{2.5}$ concentrations were not measured separately in this study, background (pre-ignition) data was used instead.

$$
V \frac{d P M_{2.5}}{d t}=\dot{v}\left(P M_{2.5}^{a m b}-P M_{2.5}\right)
$$

With an assumption of constant effective air exchange rate $(\dot{v})$ between the enclosed space and the ambient surroundings, Eq. 2 can be further simplified (Eq. 3) to calculate effective air exchange rate using post-extinguished data recorded by the sensors.

$$
\dot{v}=\frac{V}{t} \ln \left(\frac{P M_{2.5}^{0}-P M_{2.5}^{a m b}}{P M_{2.5}^{t}-P M_{2.5}^{a m b}}\right)
$$

\section{Results and Discussion}

\subsection{Sensors Calibration}

. Based on the data from collocated samplers (sensor A3 and Sidepak), a calibration factor was determined to convert sensor analog signal output to mass concentration equivalent of the Sidepak $\mathrm{PM}_{2.5}$. The Sharp GP2Y sensors demonstrated good linearity with the Sidepak $\left(\mathrm{R}^{2}=\right.$ 0.713) which is consistent with the laboratory calibration reported in the previous study [28], and the same also study reported similar slope values for different units of the same sensor. Therefore, a similar slope for the linear calibration curves was used for all the sensors used in the study which might have introduced some inaccuracy in the conversion of the analog signal output from these sensors to Sidepak equivalent $\mathrm{PM}_{2.5}$. Intercept values of the linear calibration curves were calculated by equating the background measurements from all sensors, because no spatial variability was expected before the ignition of fuel, and therefore all the sensors record the same PM levels. The values of linear calibration curve constants (slope and intercept) for the five sensors used in this study are presented in Table 2 . 
Figure 3 presents the converted sensor A3 data (mass concentration) and Sidepak data from the four runs in Household A (A-R1 to A-R4). Some of the Sidepak data for run A-R4 (Figure $3 \mathrm{D})$ is missing due to sampling problems. The first observation from Figure 3 is the difference in the saturation limits of the two instruments. The Sidepak can measure up to $20 \mathrm{mg} / \mathrm{m}^{3}$, whereas the sensors appear to saturate at $5 \mathrm{mg} / \mathrm{m}^{3}$, which is higher than the previously reported saturation concentration of $4 \mathrm{mg} / \mathrm{m}^{3}$ [28]. The difference in the saturation concentrations of the sensor could be attributed to the differences in the optical properties of the particles, which highlights the importance of calibrating any light scattering based PM measurement instrument with other techniques or by carefully evaluating the impact of refractive index of the particles.

The Sidepak had a slower response, and showed a delayed concentration growth for runs AR1, A-R2, and A-R4 (Figure 3) for the first peak, corresponding to ignition at 10:37, 12:33, and 12:48 respectively. This cannot be attributed to the sampling configuration of the sensor A3 and the Sidepak described in the previous section. The residence time in the tubing was not high enough to explain the observed delay in the Sidepak response. Another thing to note is that this delay was observed only for ignition, and therefore was not observed in run A-R3 (Figure 3), in which sampling was started few minutes after ignition owing to technical issues. Kindling was done using a few splashes of kerosene, which burned for the first few minutes, producing PM at a much lower rate than when the biomass started burning. At low PM emission rates, factors like the location of the sensor relative to the sampling probe and nearby ventilation features such as the window and the door (Figure 2A) could explain the delayed response of the Sidepak.

The sensors were saturated for a significant part for each run shown in Figure 3, and therefore, they failed to provide quantitative information for that period. It should be noted that these are rather high indoor PM concentrations. Both runs A-R2 and A-R4 (Figure 3) 
demonstrated mismatch between the PM sensor and the Sidepak towards the end of the sampling, which marks the extinguishing phase of the burn cycle.

Overall, the PM sensors demonstrated good agreement $\left(\mathrm{R}^{2}=0.713\right)$ with the Sidepak under field conditions with scope of further improvement to address the observed issues such as the delay between the responses from the two instruments, and saturation at high concentrations $\left(5 \mathrm{mg} / \mathrm{m}^{3}\right.$ in this case). A pump or fan to introduce the sample gas to the optical chamber of the PM sensor would decrease its reliance on natural dispersion.

There are few limitations associated to the PM sensors used in this study which could be addressed in future work. Mass concentrations measured by the light scattering based devices depend on the optical properties of the PM [38], and therefore there may be some deviations from the exact mass concentrations. Nevertheless, the primary purpose of data collected in this study is to facilitate comparative analysis. Also, different types of fuel were burned in the two households, but the sensors were only calibrated for Household A which limits any comparison between PM levels recorded in the two households.

\subsection{Spatio-temporal Concentration Profiles}

Figures 4 and 5 present the spatio-temporal concentration profiles in Household A and Household B respectively. Output signals from all five sensors were converted to Sidepakequivalent $\mathrm{PM}_{2.5}$ mass concentrations, as discussed in the previous section.

\subsubsection{Pre-ignition (Background)}

In Household A, sampling started before ignition in all runs except A-R3. The first peak in the PM levels marks ignition and the final decay marks extinguishing the flame (Figure 4).

The pre-ignition PM level for run A-R1 $\left(0.52 \mathrm{mg} / \mathrm{m}^{3}\right)$ was much higher than those for run A-R2 
$\left(0.07 \mathrm{mg} / \mathrm{m}^{3}\right)$ and A-R4 $\left(0.05 \mathrm{mg} / \mathrm{m}^{3}\right)$. This could be due to relatively early sampling for run AR4 (10:25) compared to other runs, where sampling started at around noon. Other households in the community of Household A also used solid fuels and were observed to cook their meal a couple of hours before noon. The high pre-ignition PM level observed for Run A-R3 (Figure 5A) was due to the emissions from the neighbours' cookstoves. This finding suggests that even if a household switches to cleaner fuel alternatives, they still might be exposed to elevated PM levels from the neighbours. In addition to an indoor air quality issue, households using solid fuels also impact the ambient air quality.

\subsubsection{Cooking Phase}

The highly variable concentration profiles during the cooking phase (Figure 4 and Figure 5) are typical for biomass combustion in uncontrolled settings [15, 16]. The multiple peaks correspond to events like refuelling, blowing air to rekindle the fire, and various cooking activities such as adding and removing a pot. In Household A, sensor A3 recorded the highest concentration levels and also the longest saturation time. This observation can be explained by its location, 1.83 meters directly above the cookstove in the natural path of the plume caused by upward convection, which often also leads to pollutant stratification in the vertical direction [22]. This vertical concentration gradient was also reflected by data from sensors A3 and A4 for runs A-R1 and A-R2 (Figure 4A and 4B). Sensor A4, used for two runs (A-R1 and A-R2), was furthest from the ventilation sources but detected lower PM levels than other kitchen sensors installed higher up.

Sensors A1 and A2 were next closest to the cookstove, after sensor A3. Cookstove emissions (plume) tend to move towards openings like windows and doors via diffusion, and depending on the air flow direction, convection as well. Therefore, PM level trends at position 
A1 and A2 are, as expected, similar to the trends observed at position A3. In all four runs (Figure 4A-4D), sensors A1 and A2 tracked the PM level profile measured by sensor A3 but demonstrated lower PM levels due to dilution as their location was further away from the plume and close to the ventilation sources. Also, the sensors on the window (A1) and door (A2) demonstrated higher fluctuations than the other two locations inside the kitchen (A3 and A4) for all runs. These two sensors were installed at the boundary of the kitchen and outer environment (Figure 2A), exposing them to air exchange and dilution. Lower signals from these two sensors indicate natural dilution.

Sensor A5 recorded the lowest PM levels (Figure 4A-4D), which can be explained by its location outside of the kitchen in the ambient environment. Compared to the background or preignition levels, elevated PM levels were recorded by sensor A5 for all four runs (Figure 4A4D), and the highest PM levels were observed during the first half of run A-R4 (Figure 4D). The fuel used for the first half of this run was rice straw, which burns faster than fuelwood and also generates an exceptionally high amount of particulate matter (also visible by the enhanced smoke plume). The Sidepak recorded the highest concentration it can measure $\left(20 \mathrm{mg} / \mathrm{m}^{3}\right)$ during the burn cycle of rice straw (Figure 3D). The high PM generation rate caused a high signal from sensor A5 even after natural dilution. For runs A-R1, A-R2, A-R3, and the latter half of run A-R4 (Figure 5), fuelwood was used, which produced much less smoke than rice straw. Although flow rate measurements could not be taken, even forced ventilation might fail to provide sufficient air exchange to cope up with high emissions from solid fuels like rice straw. It is important to transition to cleaner fuel alternatives, although fuel transitioning faces many challenges such as resource constraints, poverty and lack of an appropriate policy framework [39]. 
Figure 5 presents the results from the two runs in Household B. Sensor B1 detected the highest concentrations, followed by sensor B3, owning to their lower distances from the cookstove. Sensors B1 and B3 recorded similar PM levels and trends in run B-R1 (Figure 5A), indicating low spatial variability in the room just outside the kitchen. But in run B-R2 (Figure 5B), sensor B3 detected PM levels lower than that from sensor B1 for the whole run, except at the end. Since the same fuel and stove were used for the two runs in Household B, the observed difference were attributed to the differences in the natural air exchange between the household space and ambient environment.

Due to limited number of sensors deployed, measurement at B6 in household B (Figure 2B) was taken in only one run (B-R1) for 45 minutes starting at 16:17 when sensor B2 was moved to the position B6. In Figure 5A, the three sensors in the bedroom (B5, B4 and B2) showed similar trends, but with a delay in responses inversely proportional to their distances from the cookstove indicating the dispersion of PM through the bedroom. Also, the data from sensor B5 demonstrated more fluctuations than sensors B2 and B4, which could be attributed to its proximity to the door making it more susceptible to air exchange, whereas sensors B2 and B4 were located in a relatively dead zone. After about fifteen minutes from ignition, all sensors except B6 remained saturated for a significant fraction of the sampling time (Figure 5A), which disables any comparative analysis during this period, but it does indicate that PM levels were very high throughout the household. Therefore, it emphasizes that personal exposure due to household air pollution is not limited to the kitchen and the person cooking.

\subsubsection{Post-extinguished Decay Phase}

Experimental and modelling work has been done by several researchers to understand the distribution and decay of pollutants inside a closed space with controlled ventilation [22-24, 40- 
43]. Bouilly et al. [24] studied the effect of ventilation characteristics and particle size on the particle decay rate in a model room; and observed that the decay in concentration is particle size dependent. Since sampling was continued even after extinguishing the cookstove for the runs B-R1 and B-R2 at 16:46 and 17:02, average post-extinguished decay rates of PM levels can be calculated and used as a proxy for air exchange between the household and the ambient environment.

In Household A, comparable average PM level decay rates (Eq. 1) and effective air exchange rates (Eq. 3) were observed: A-R2, $0.52 \mathrm{mg} / \mathrm{m}^{3}-\mathrm{min}$ and $3.92 \mathrm{~m}^{3} / \mathrm{min}$; A-R3, 0.72 $\mathrm{mg} / \mathrm{m}^{3}-\mathrm{min}$ and $3.39 \mathrm{~m}^{3} / \mathrm{min}$; and A-R $4,0.54 \mathrm{mg} / \mathrm{m}^{3}-\mathrm{min}$ and $3.91 \mathrm{~m}^{3} / \mathrm{min}$. Similarly, average PM level decay rates of $0.26 \mathrm{mg} / \mathrm{m}^{3}$-min and $0.87 \mathrm{mg} / \mathrm{m}^{3}-\mathrm{min}$ were observed for runs B-R1 and B-R2 respectively. Though the interior volume of Household B was significantly higher than that of Household A, comparable decay rates for the two households can be explained by higher effective air exchange rates in Household $B\left(B-R 1: 7.68 \mathrm{~m}^{3} / \mathrm{min}\right.$ and $B-R 2: 37.40 \mathrm{~m}^{3} / \mathrm{min}$, which is a function of air flow rates and the area available for ventilation.

There was no forced ventilation in Household B, and therefore the threefold higher decay rate for run B-R2 compared to run B-R1 can be attributed to a higher effective air exchange rate (B-R1: $7.68 \mathrm{~m}^{3} / \mathrm{min}$ and B-R2: $37.40 \mathrm{~m}^{3} / \mathrm{min}$ ) on that day than on the day of run B-R1. A lower air exchange rate for run B-R1 could also explain why all sensors (except B6) were saturated during half of the sampling time, and low spatial variability. This observation also highlights that in households with no forced ventilation, typical of most rural households, cookstove emissions can linger for durations comparable to the actual cooking session. Since the same fuel and cookstove was used in both runs in Household B, the differences in the spatio-temporal PM 
levels in the two runs (Figure 5) emphasize the importance of looking beyond the cookstoves and encourage a holistic approach to tackling household air pollution.

\section{Conclusions}

The utility of a low-cost wireless sensor network to measure spatio-temporal PM levels in households using cookstoves was demonstrated. The data from the sensors agreed well $\left(\mathrm{R}^{2}=0.713\right)$ with the reference measurement by a conventional instrument, the Sidepak. Data from the sensor network established the importance of spatio-temporal measurements, which provided insights into the effects of multiple factors such as the household layout and ventilation characteristics. Poorly ventilated small spaces like the kitchen in Household A, results in little spatial variability. The higher aerosol generation rate from rice straw combustion compared to fuelwood led to significantly high PM levels even in the area outside the kitchen in the ambient environment. In Household B, where the kitchen adjoined the living space and the bedroom, PM levels comparable to the kitchen were measured throughout the house highlighting that personal exposure due to household air pollution is not limited to the kitchen and the person cooking.

Lacking forced ventilation, both households relied on natural air exchange, which was found to be insufficient in reducing PM exposure. Significant differences were observed for the PM level decay rate for two runs in the Household $B\left(0.26 \mathrm{mg} / \mathrm{m}^{3}-\mathrm{min}\right.$ and $\left.0.87 \mathrm{mg} / \mathrm{m}^{3}-\mathrm{min}\right)$, owing to different effective air exchange rates $\left(7.68 \mathrm{~m}^{3} / \mathrm{min}\right.$ and $\left.37.40 \mathrm{~m}^{3} / \mathrm{min}\right)$. Moreover, even for the highest decay rate and effective air exchange rate observed, cookstove emissions lingered inside the household for a period comparable to the cooking time.

High background PM levels were observed in a few cases, even when the cookstove was not lit, which was attributed to emissions from neighboring household cookstoves. Therefore, 
even if one household in a community dominated by solid fuel combustion switches to a cleaner fuel, the exposure of the household members might not decrease significantly because of the high ambient concentration. In such scenarios, wireless sensors will also be helpful in measurements at macroscale and can be related to meteorological data to study their effect on pollutant transport and fate. The arrangement of such wireless sensors with routers and coordinators can be customized for deployment in large areas such as a community or even a city where measured PM levels can be stored in a central data repository.

\section{Acknowledgements}

This work was partially supported by the International Center for Advanced Renewable Energy and Sustainability (I-CARES) Washington University in St. Louis (WUSTL) and the McDonnell Academy Global Energy and Environmental Partnership (MAGEEP). S. Patel thanks the McDonnell International Scholars Academy of WUSTL, and Arch Coal Inc. for graduate fellowship. Authors thank graduate students of School of Studies in Chemistry at Pandit Ravishankar Shukla University in Raipur, India, for providing field support. Partial support from NSF (grant no. AGS1455215 and CBET 1437933) and NASA (grant no. NNX15AI66G) are also gratefully acknowledged. 


\section{References:}

1. Cheng, Z., et al., Status and characteristics of ambient PM2.5 pollution in global megacities. Environment International, 2016. 89-90: p. 212-221.

2. Spengler, J. and K. Sexton, Indoor air pollution: a public health perspective. Science, 1983. 221(4605): p. 9-17.

3. Zhang, J.J. and K.R. Smith, Indoor air pollution: a global health concern. British medical bulletin, 2003. 68(1): p. 209-225.

4. Zhou, J., et al., Particle exposure during the 2013 haze in Singapore: Importance of the built environment. Building and Environment, 2015. 93, Part 1: p. 14-23.

5. Smith, K.R., et al., Indoor air pollution in developing countries and acute lower respiratory infections in children. Thorax, 2000. 55(6): p. 518-532.

6. Bruce, N., R. Perez-Padilla, and R. Albalak, Indoor air pollution in developing countries: a major environmental and public health challenge. Bulletin of the World Health Organization, 2000. 78(9): p. 1078-1092.

7. Ekici, A., et al., Obstructive airway diseases in women exposed to biomass smoke. Environmental Research, 2005. 99(1): p. 93-98.

8. Pokhrel, A.K., et al., Biomass stoves and lens opacity and cataract in Nepalese women. Optometry and vision science: official publication of the American Academy of Optometry, 2013.90(3): p. 257.

9. Pokhrel, A.K., et al., Case-control study of indoor cooking smoke exposure and cataract in Nepal and India. International Journal of Epidemiology, 2005. 34(3): p. 702-708.

10. Kim Oanh, N.T., et al., Emission of particulate matter and polycyclic aromatic hydrocarbons from select cookstove-fuel systems in Asia. Biomass and Bioenergy, 2005. 28(6): p. 579-590.

11. Smith, K.R., et al., Personal child and mother carbon monoxide exposures and kitchen levels: methods and results from a randomized trial of woodfired chimney cookstoves in Guatemala (RESPIRE). Journal of Exposure Science and Environmental Epidemiology, 2010. 20(5): p. 406-416.

12. Albalak, R., et al., Indoor respirable particulate matter concentrations from an open fire, improved cookstove, and LPG/open fire combination in a rural Guatemalan community. Environmental science \& technology, 2001. 35(13): p. 2650-2655.

13. Dionisio, K.L., et al., Household concentrations and exposure of children to particulate matter from biomass fuels in The Gambia. Environmental science \& technology, 2012. 46(6): p. 3519-3527.

14. Balakrishnan, K., et al., Exposure assessment for respirable particulates associated with household fuel use in rural districts of Andhra Pradesh, India. Journal of Exposure Science and Environmental Epidemiology, 2004. 14: p. S14-S25.

15. Sahu, M., et al., Evaluation of Mass and Surface Area Concentration of Particle Emissions and Development of Emissions Indices for Cookstoves in Rural India. Environmental Science \& Technology, 2011. 45(6): p. 2428-2434.

16. Leavey, A., et al., Real-time particulate and $C O$ concentrations from cookstoves in rural households in Udaipur, India. Environmental science \& technology, 2015. 49(12): p. 7423-7431. 
17. Kar, A., et al., Real-Time Assessment of Black Carbon Pollution in Indian Households Due to Traditional and Improved Biomass Cookstoves. Environmental Science \& Technology, 2012. 46(5): p. 2993-3000.

18. Leavey, A., et al., Real-time particulate and CO concentrations from cookstoves in rural households in Udaipur, India. Environmental science \& technology, 2015.

19. Armendáriz-Arnez, C., et al., Indoor particle size distributions in homes with open fires and improved Patsari cook stoves. Atmospheric Environment, 2010. 44(24): p. 28812886.

20. Roden, C.A., et al., Emission Factors and Real-Time Optical Properties of Particles Emitted from Traditional Wood Burning Cookstoves. Environmental Science \& Technology, 2006. 40(21): p. 6750-6757.

21. Clark, M.L., et al., Indoor air pollution, cookstove quality, and housing characteristics in two Honduran communities. Environmental research, 2010. 110(1): p. 12-18.

22. Johnson, M., et al., Modeling indoor air pollution from cookstove emissions in developing countries using a Monte Carlo single-box model. Atmospheric Environment, 2011. 45(19): p. 3237-3243.

23. Chung, K.-C. and S.-P. Hsu, Effect of ventilation pattern on room air and contaminant distribution. Building and Environment, 2001. 36(9): p. 989-998.

24. Bouilly, J., et al., Effect of ventilation strategies on particle decay rates indoors: An experimental and modelling study. Atmospheric Environment, 2005. 39(27): p. 48854892.

25. Dasgupta, S., et al., Who suffers from indoor air pollution? Evidence from Bangladesh. Health Policy and Planning, 2006. 21(6): p. 444-458.

26. Dasgupta, S., et al., Improving indoor air quality for poor families: a controlled experiment in Bangladesh. Indoor Air, 2009. 19(1): p. 22-32.

27. Clark, M.L., et al., Health and household air pollution from solid fuel use: the need for improved exposure assessment. Environmental health perspectives, 2013. 121: p. 11201128.

28. Wang, Y., et al., Laboratory Evaluation and Calibration of Three Low-Cost Particle Sensors for Particulate Matter Measurement. Aerosol Science and Technology, 2015. 49(11): p. 1063-1077.

29. Bhattacharya, S., S. Sridevi, and R. Pitchiah. Indoor air quality monitoring using wireless sensor network. in Sensing Technology (ICST), 2012 Sixth International Conference on. 2012. IEEE.

30. Chung, W.-Y. and S.-J. Oh, Remote monitoring system with wireless sensors module for room environment. Sensors and Actuators B: Chemical, 2006. 113(1): p. 64-70.

31. Kim, J.-J., S.K. Jung, and J.T. Kim, Wireless monitoring of indoor air quality by a sensor network. Indoor and built Environment, 2010. 19(1): p. 145-150.

32. Kim, J.-Y., C.-H. Chu, and S.-M. Shin, ISSAQ: An integrated sensing systems for realtime indoor air quality monitoring. IEEE Sensors Journal, 2014. 14(12): p. 4230-4244.

33. Rajasegarar, S., et al. High resolution spatio-temporal monitoring of air pollutants using wireless sensor networks. in Intelligent Sensors, Sensor Networks and Information Processing (ISSNIP), 2014 IEEE Ninth International Conference on. 2014. IEEE.

34. Sousan, S., et al., Inter-comparison of low-cost sensors for measuring the mass concentration of occupational aerosols. Aerosol Science and Technology, 2016. 50(5): p. 462-473. 
35. Patel, S., et al., Characterization of gaseous and particulate pollutants from gasificationbased improved cookstoves. Energy for Sustainable Development, 2016. 32: p. 130-139.

36. Li, C., et al., Personal PM2.5 and indoor CO in nomadic tents using open and chimney biomass stoves on the Tibetan Plateau. Atmospheric Environment, 2012. 59: p. 207-213.

37. Commodore, A.A., et al., A pilot study characterizing real time exposures to particulate matter and carbon monoxide from cookstove related woodsmoke in rural Peru. Atmospheric Environment, 2013. 79: p. 380-384.

38. Friedlander, S.K., Smoke, dust and haze: Fundamentals of aerosol behavior. New York, Wiley-Interscience, 1977. 333 p., 1977. 1.

39. Patel, S., et al., A model for cost-benefit analysis of cooking fuel alternatives from a rural Indian household perspective. Renewable and Sustainable Energy Reviews, 2016. 56: p. 291-302.

40. Sandberg, M. and M. Sjöberg, The use of moments for assessing air quality in ventilated rooms. Building and Environment, 1983. 18(4): p. 181-197.

41. Posner, J.D., C.R. Buchanan, and D. Dunn-Rankin, Measurement and prediction of indoor air flow in a model room. Energy and Buildings, 2003. 35(5): p. 515-526.

42. Baughman, A., A. Gadgil, and W. Nazaroff, Mixing of a point source pollutant by natural convection flow within a room. Indoor air, 1994. 4(2): p. 114-122.

43. Afshari, A., U. Matson, and L.E. Ekberg, Characterization of indoor sources of fine and ultrafine particles: a study conducted in a full-scale chamber. Indoor air, 2005. 15(2): p. 141-150. 


\section{List of Tables}

Table 1: Summary of experimental plan for the two households

Table 2: Calibration factors (slope and intercept) for the five Sharp GP2Y sensors used for converting their analog output to Sidepak equivalent $\mathrm{PM}_{2.5}$ levels 
Table 1: Summary of experimental plan for the two households

\begin{tabular}{cccc}
\hline Household & Run \# & Run Code & Fuel \\
\hline \multirow{3}{*}{ A } & 1 & A-R1 & Fuelwood \\
& 2 & A-R2 & Fuelwood \\
& 3 & A-R3 & Fuelwood \\
& 4 & A-R4 & Rice straw \\
& & & and fuelwood \\
& & & Dung cakes \\
B & 5 & B-R1 & Dung cakes \\
\hline
\end{tabular}


Table 2: Calibration factors (slope and intercept) for the five Sharp GP2Y sensors used for converting their analog output to Sidepak equivalent $\mathrm{PM}_{2.5}$ levels

\begin{tabular}{cccc}
\hline Sensor \# & Locations & Slope & Intercept \\
\hline 1 & A1, B1 & 0.00954 & -1.88 \\
2 & A2, B2, B6 & 0.00954 & -1.54 \\
3 & A3, B3 & 0.00954 & -1.60 \\
4 & A4, B4 & 0.00954 & -2.16 \\
5 & A5, B5 & 0.00954 & -1.73 \\
\hline
\end{tabular}




\section{List of figures}

Figure 1: PM sensor assembly, which includes a Sharp GP2Y sensor, a router mounted on a chip board, and a $5 \mathrm{~V}$ lithium ion battery.

Figure 2: Top view showing the layout of the (A) upper level of the household with the isolated kitchen and, (B) household with kitchen interconnected with other room in the household. Only the doors and windows which were opened during sampling are shown in the layout. Positions (A1-A5 in Household A and B1-B6 in Household B) where PM sensors were installed are marked with the height in the parentheses

Figure 3: Analog signal from the PM sensor at location A3 in household A, converted to mass concentration, and $\mathrm{PM}_{2.5}$ levels measured by the collocated Sidepak.

Figure 4: Real-time PM concentrations measured by the PM sensors installed at different locations in household A over four runs: (A) A-R1, (B) A-R2, (C) A-R3, and (D) A-R4.

Figure 5: Real-time PM concentrations measured by the PM sensors installed at different locations in household B over three runs: (A) B-R1 and (B) B-R2. 


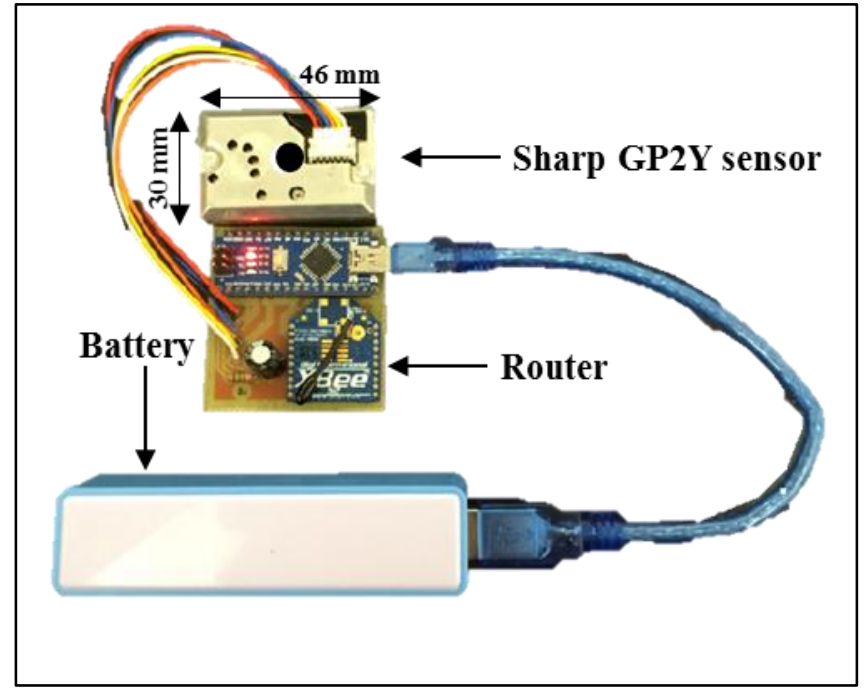

Figure 1: PM sensor assembly, which includes a Sharp GP2Y sensor, a router mounted on a chip board, and a $5 \mathrm{~V}$ lithium ion battery. The battery can be significantly reduced in size in next generation devices. 


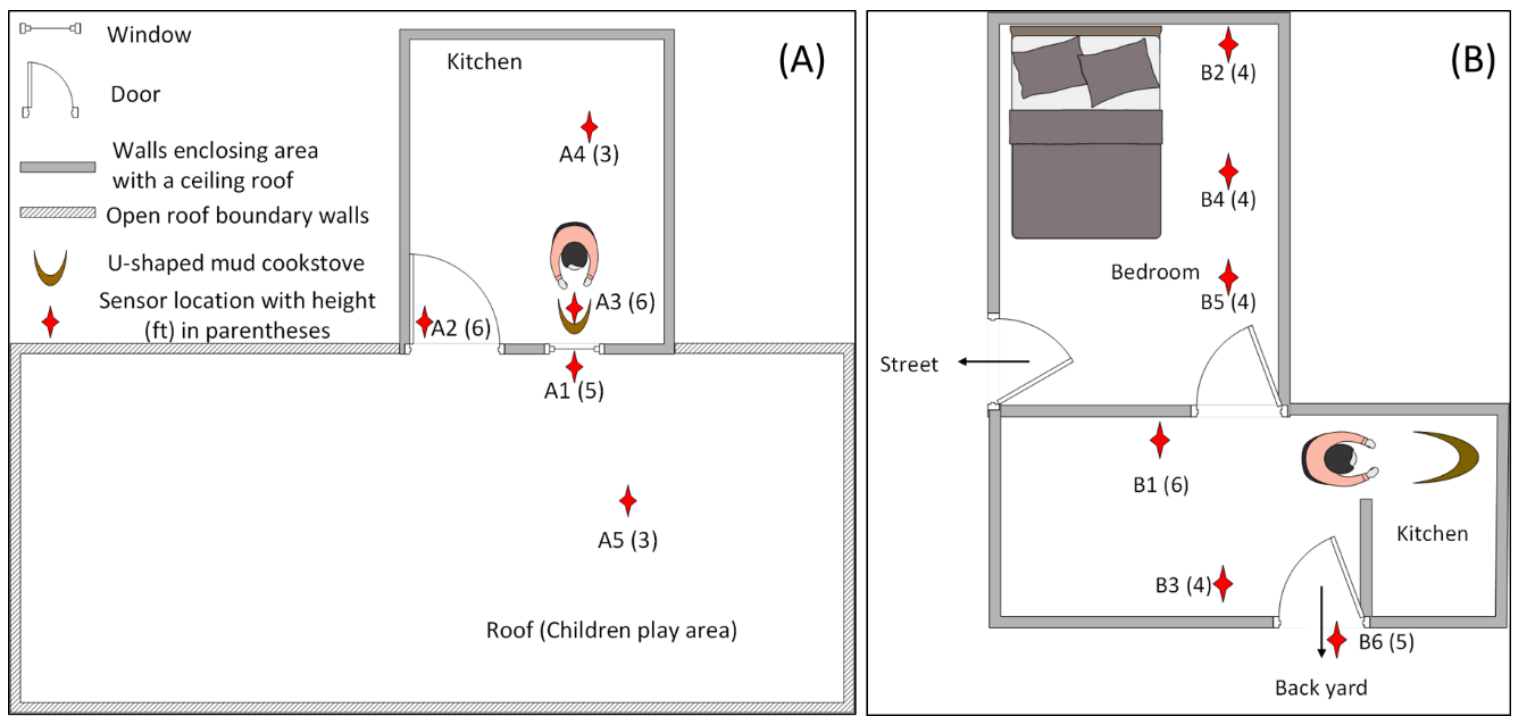

Figure 2: Top view showing the layout of the (A) upper level of the household with the isolated kitchen and, (B) household with kitchen interconnected with other room in the household. Only the doors and windows which were opened during sampling are shown in the layout. Positions (A1-A5 in Household A and B1-B6 in Household B) where PM sensors were installed are marked with the height in the parentheses 

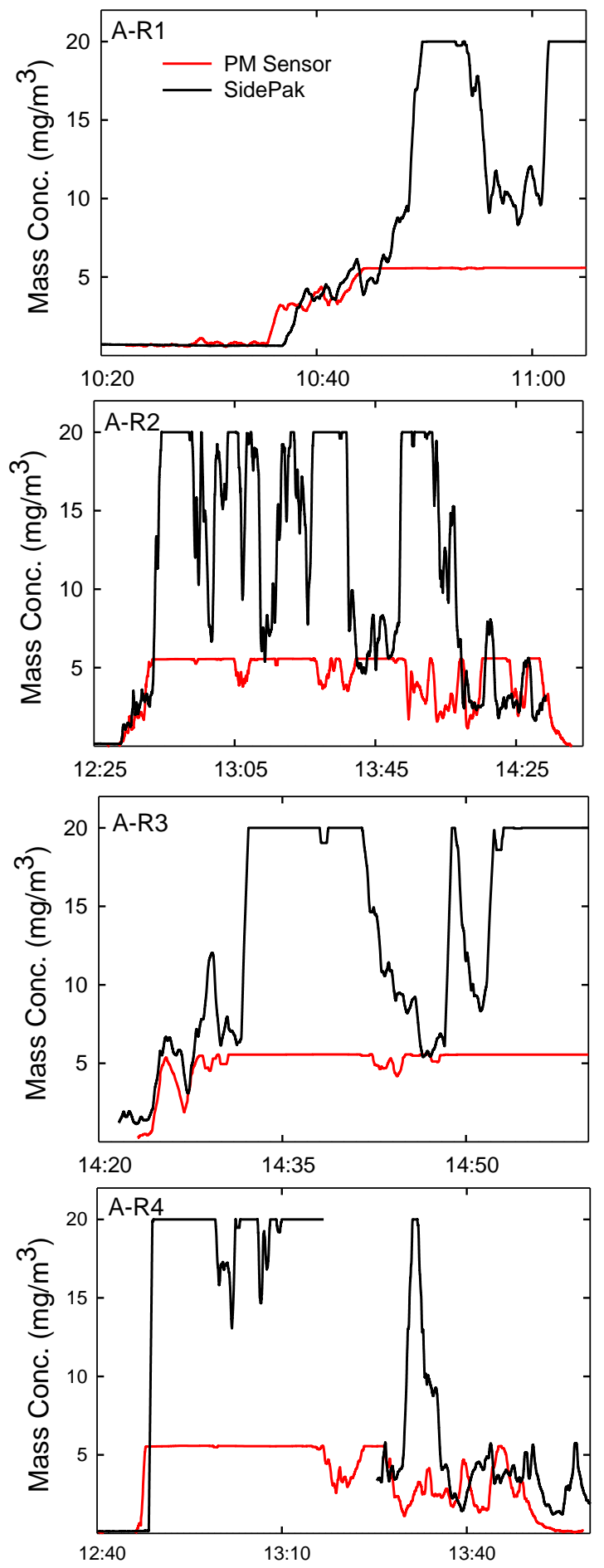

Figure 3: Analog signal from the PM sensor at location A3 in household A, converted to mass concentration, and $\mathrm{PM}_{2.5}$ levels measured by the collocated Sidepak. 

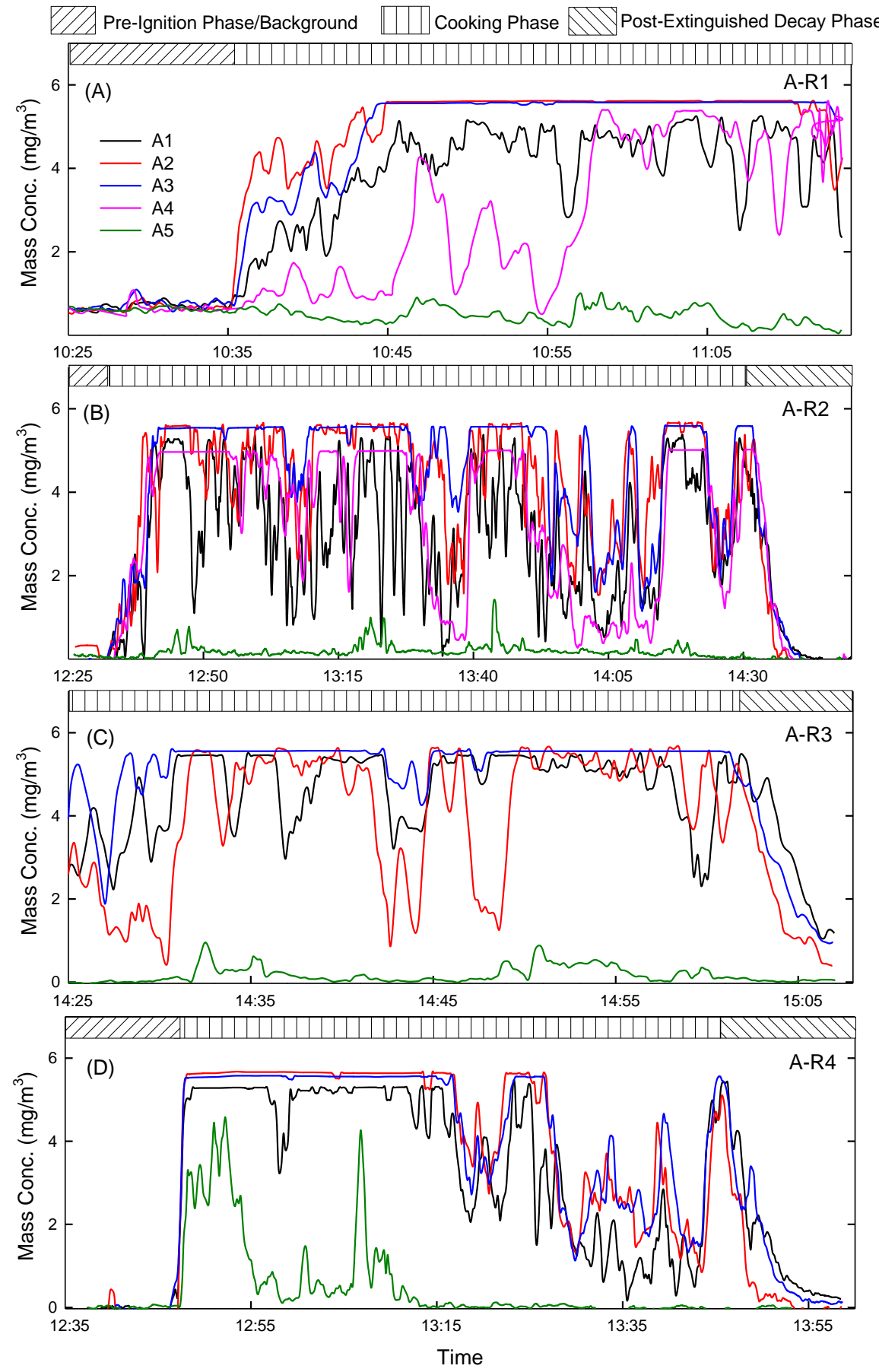

Figure 4: Real-time PM concentrations measured by the PM sensors installed at different locations in household A over four runs: (A) A-R1, (B) A-R2, (C) A-R3, and (D) A-R4 


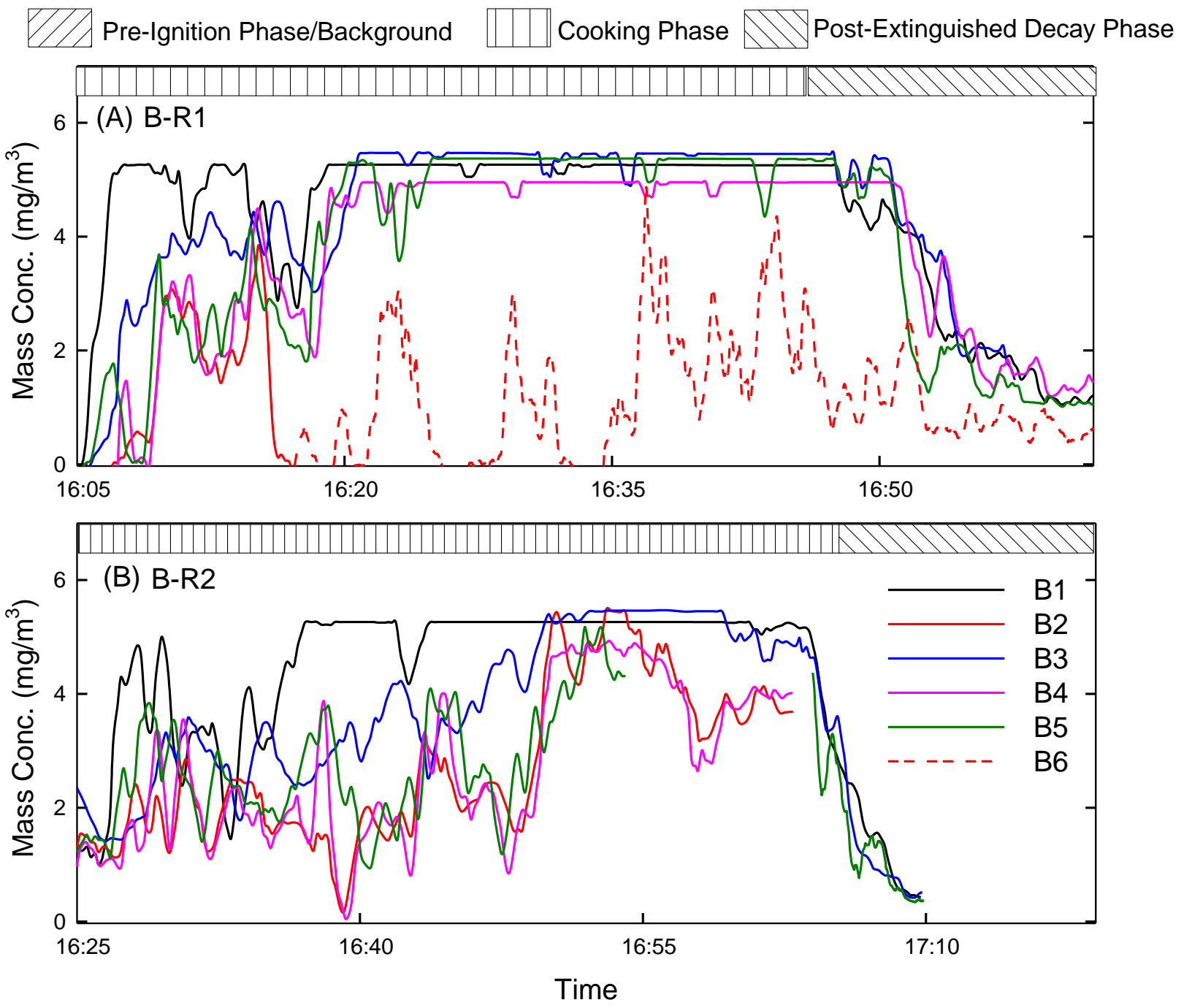

Figure 5: Real-time PM concentrations measured by the PM sensors installed at different locations in household B over three runs: (A) B-R1 and (B) B-R2. 